
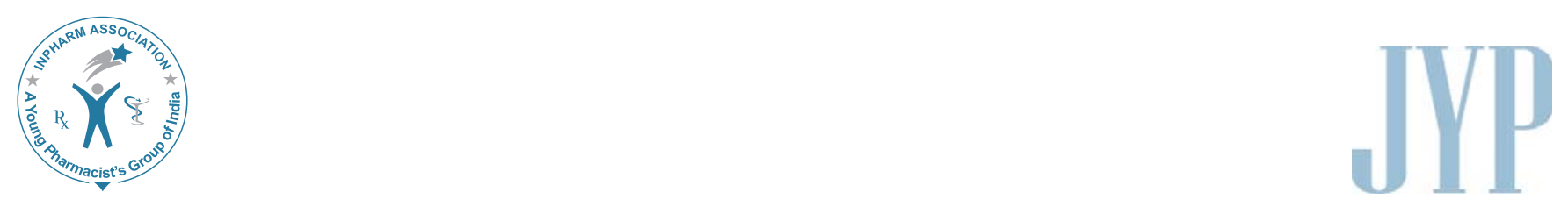

\title{
Investigation of the Mechanisms Underlying the Gastroprotective Effect of Cymbopogon Citratus Essential Oil
}

\author{
Fernandes $\mathrm{CN}^{1}$, De Souza HF${ }^{1}$, De Oliveria G'1, Costa JGM¹, Kerntopf MR¹, \\ Campos AR ${ }^{1,2}$ \\ ${ }^{1}$ Programa de Pós-Graduação em Bioprospecção Molecular, Universidade Regional do Cariri, Crato, CE, \\ ${ }^{2}$ Vice-Reitoria de Pesquisa e Pós-Graduação, UNIFOR, Fortaleza, Ceará, Brazil
}

Address for correspondence: Dr. José Galberto M. da Costa; E-mail: galberto.martins@urca.br

\begin{abstract}
Cymbopogon citratus is a medicinal plant popularly used in Brazil for the treatment of various diseases, and the research interest in this plant is justifiable because of its potential medicinal value in stomachache and gastric ulcer. This study was aimed to test the validity of this practice by using experimental models of gastric ulcer and to clarify the mechanisms of gastroprotection by C. citratus leaves essential oil (EOCC). EOCC was evaluated for the ability to protect the gastric mucosa against injuries caused by necrotizing agents (absolute ethanol and aspirin) in rodents. The results of this study revealed that EOCC posses a dose-independent antiulcer effect against the different experimental models. EOCC pretreatment depicted a higher preventive index in ethanol-(88\%) and aspirin-induced $(76 \%)$ acute ulceration. On pretreatment of mice with indomethacin, the cyclooxygenase inhibitor slightly suppressed the gastroprotective effect of EOCC (48.5\%). Furthermore, EOCC gastroprotection was not attenuated in mice pretreated with L-NAME $(85.2 \%)$, glibenclamide $(100 \%)$, or yohimbine $(79.7 \%)$, the respective inhibitors of nitric oxide synthase, $\mathrm{K}_{\text {ATP }}^{+}$channel activation, and $\alpha_{2}$ receptors. These results confirmed the traditional use of $C$. citratus for the treatment of gastric ulcer. Thus, we provide the first evidence that EOCC reduces gastric damage induced by ethanol, at least in part, by mechanisms that involve endogenous prostaglandins.
\end{abstract}

Key words: Cymbopogon citratus, essential oil, gastroprotection, mechanisms

\section{INTRODUCTION}

Gastric ulcers are caused due to imbalances between offensive and defensive factors of the gastric mucosa. ${ }^{[1]}$

\begin{tabular}{|c|l|}
\hline \multicolumn{2}{|c|}{ Access this article online } \\
\hline Quick Response Code: & \\
\hline & Website: \\
\hline & www.jyoungpharm.in \\
& \\
\hline
\end{tabular}

Oral administration of absolute ethanol in rats is noxious for the stomach, affecting the gastric mucosa topically by disrupting its barrier and provoking pronounced microvascular changes in few minutes after its application. Thus, rapid and strong vasoconstriction is accompanied by rapid and vigorous arteriolar dilation, and this combination of microvascular events induces damage in mucosal capillaries. ${ }^{[2,3]}$ Pathophysiology of ulcer is due to an imbalance between aggressive factors (acid, pepsin, Helicobacter pylori, and non-steroidal anti-inflammatory agents) and local mucosal defensive factors (mucus bicarbonate, blood flow, and prostaglandins). ${ }^{[4]}$ The 
lipid peroxidation mediated by reactive oxygen species is an important cause of destruction and damage to cell membranes, and it is involved in the pathogenesis of acute mucosal injury induced by ethanol, ischemia-reperfusion, and indomethacin. ${ }^{[5,6]}$

Natural medicinal products have been used for millennia for the treatment of multiple ailments. Although many have been superseded by conventional pharmaceutical approaches, there is currently a resurgence of interest in the use of natural bioactive products by the general public, with many healthy subjects and patients taking them for the prevention and treatment of multiple conditions, including gastrointestinal disorders and postoperative recovery. ${ }^{[7]}$ Unfortunately, current evidence of the scientific validity of many of these traditional and commercial compounds is severely limited. ${ }^{[6]}$

Cymbopogon citratus (DC.) Stapf, popularly known as citronella grass or lemongrass, belongs to the Poaceae family, which comprises approximately 500 genus and 8,000 herb species. The plant is a perennial grass that is widespread throughout the world, mainly in the tropical and savannah regions. The tea from its leaves has been widely used as an antiseptic, antifever, antidyspeptic, carminative, tranquilizer, and stomachic. Several investigations have demonstrated the sedative, central nervous system depressor, analgesic, antimicrobial, and fungistatic activities of C. citratus leaves. Neral, geranial, limonene, citronellal, myrcene, and geraniol were identified as maker compounds in the essential oils of C. citratus. ${ }^{[8]}$ Previous results of acute oral toxicity showed $C$. citratus to be of low toxicity and as such could be considered relatively safe on acute exposure. ${ }^{[0]}$

Although used in traditional folk medicine in Brazil for the treatment of gastric disturbances, there is no scientific evidence that establishes this activity. Here we report the effect of the essential oil extracted from $C$. citratus leaves on experimental gastric ulcer in mice.

\section{MATERIALS AND METHODS}

Plant material and oil isolation

Fresh leaves $(1.750 \mathrm{~g})$ of $C$. citratus were collected in the Medicinal and Aromatic Plant Garden at Pimenta Campus of Regional University of Cariri, Crato, CE, Brazil, in March 2007. Leaves were triturated and extracted by hydrodistillation for $2 \mathrm{~h}$ using a Clevenger-type apparatus. C. citratus leaves essential oil (EOCC) was collected and then dried using anhydrous sodium sulfate and subsequently stored under low light conditions at $<10^{\circ} \mathrm{C}$ until analysis.
Essential oil analysis

Analysis of EOCC was performed using Gas Chromatography-Mass Spectroscopy (GC/MS QP5050A, Shimadzu, Kyoto, Japan). The instrument was equipped with a GC-17A gas chromatograph supplied with DB-5HT capillary column $(30 \mathrm{~m} \times 0.251 \mathrm{~mm}, 0.1 \mu \mathrm{m}$ film thickness); carrier gas, helium $1.0 \mathrm{~mL} / \mathrm{min}$; column inlet pressure, 56.7 $\mathrm{kPa}$; column flow, $1.0 \mathrm{~mL} / \mathrm{min}$; linear velocity, $36.5 \mathrm{~cm} / \mathrm{s}$; total flow, $32 \mathrm{~mL} / \mathrm{min}$; injector temperature, $250^{\circ} \mathrm{C}$; detector temperature, $270^{\circ} \mathrm{C}$; column temperature, $60(2 \mathrm{~min})$ to $180^{\circ} \mathrm{C}(4 \mathrm{~min})$ at $4^{\circ} \mathrm{C} / \mathrm{min}$, then 180 to $260^{\circ} \mathrm{C}$ at $10^{\circ} \mathrm{C} / \mathrm{min}$ (10 min); mass spectrometer operating conditions, $70 \mathrm{eV}$ ionization energy. Identification of individual components was based on their mass spectral fragmentation using two computer library MS searches (wiley 229), retention indices, and comparison with literature data. EOCC represented $0.65 \%$ of their total fresh weight. Chromatographic analysis permitted the identification and quantification of $99.34 \%$ of the volatile components of the oil, including geranial $(45.47 \%)$, neral $(37.42 \%)$, and myrcene $(12.44 \%)$, as presented in Table 1.

\section{Chemicals and drugs}

The following drugs and chemicals were used: absolute ethanol (EtOH; BDH, UK); N-G-nitro-L-arginine methyl ester (L-NAME), yohimbine, and glibenclamide (Sigma Chemical Company, St. Louis, MO); and indomethacin (Indocid $^{\circledR}$, Merck Sharp and Dohme, Brazil). All other chemicals used were of analytical reagent grade (Merck). OECC was first dissolved in Tween 80 and subsequently diluted in distilled water, and the resulting solutions of EOCC did not exceed concentration of Tween 80 beyond $2 \%$. Other drugs were dissolved either in physiological saline or distilled water. Drug concentrations were adjusted for treatment to give a volume of $10 \mathrm{~mL} / \mathrm{kg}$. In pilot studies, $2 \%$ Tween 80 (vehicle) demonstrated no per se effect or influence on the ulcerogenicity of ethanol.

\begin{tabular}{|c|c|c|c|}
\hline Component & RT (min) & $\mathrm{KI}_{\text {exp }}{ }^{*}$ & Leaf oil (\%) \\
\hline Myrcene & 4.4 & 990 & 12.44 \\
\hline Trans- $\beta$-ocimene & 5.4 & 1047 & 0.24 \\
\hline Linalool & 7.0 & 1100 & 0.66 \\
\hline Borneol & 8.7 & 1162 & 0.67 \\
\hline Terpinen-4-ol & 9.3 & 1180 & 1.14 \\
\hline Neral & 11.1 & 1241 & 37.42 \\
\hline Trans-geraniol & 11.6 & 1257 & 1.6 \\
\hline Geranial & 12.2 & 1273 & 45.17 \\
\hline
\end{tabular}

*Retention indices experimental. $n$-Alkanes were used as reference points in the calculation of relative retention indices 


\section{Animals}

Male Swiss albino mice (20-25 g) obtained from the Central Animal House of Medicine Faculty of Juazeiro do Norte were used. They were housed in environmentally controlled conditions $\left(22^{\circ} \mathrm{C}, 12\right.$-h light-dark cycle), with free access to standard pellet diet (Purina do Brasil LTDA, São Paulo, Brazil) and water ad libitum. Animals were kept in cages with raised floors to prevent coprophagy. They were fasted over a period of $15 \mathrm{~h}$ and were habituated to the test environment for $2 \mathrm{~h}$ before the experimentation. The experimental protocols were approved by the Animal Care and Use Committee of the Regional University of Ceará in accordance with the ethical guidelines of National Institute of Health, Bethseda, MD.

Gastric damage induced by ethanol

Acute gastric lesions were induced in mice ( $n=8 /$ group) by intragastric administration of absolute ethanol $(96 \%)$ in a volume of $0.2 \mathrm{~mL}$ (using orogastric metal tube), EOCC dissolved in Tween (2\% in distilled water as vehicle) was administered at oral doses of $50-400 \mathrm{mg} / \mathrm{kg}, 60 \mathrm{~min}$ before ethanol application. Vehicle (2\% Tween 80$)$-treated group was included as negative control. Thirty minutes after ethanol administration, the animals were killed by cervical dislocation, stomachs were removed, opened along the greater curvature, and the area of gastric lesions was measured by planimetry, using a transparent grid. The lesion area in each animal was measured in $\mathrm{mm}^{2}$ and was expressed in $\%$ in relation to total area of corpus.

Gastric damage induced by aspirin

Mice in groups ( $n=8 /$ group) were treated with EOCC (200 and $400 \mathrm{mg} / \mathrm{kg}$, per oros [p.o.]) or vehicle (2\% Tween 80 in a volume of $10 \mathrm{~mL} / \mathrm{kg}$ ). One hour after treatment, each animal received an oral dose of $500 \mathrm{mg} / \mathrm{kg}$ aspirin and they were killed $4 \mathrm{~h}$ later. Stomachs were removed, immersed in $5 \%$ formalin for $30 \mathrm{~min}$, and then opened along the greater curvature to register the incidence and extent of ulceration. The mean ulcer score for each animal was calculated and compared between groups.

Effects of yohimbine, indomethacin, L-NAME, and glibenclamide pretreatments on EOCC gastroprotection

In mechanistic studies, separate experiments were realized to examine the role of $\alpha_{2}$-receptors, prostaglandins, nitric oxide, and $\mathrm{K}^{+}{ }_{\text {ATP }}$ channel activation on the gastroprotective effect of EOCC $(200 \mathrm{mg} / \mathrm{kg})$, using appropriate antagonists, yohimbine $(2 \mathrm{mg} / \mathrm{kg}$, intraperitoneal [i.p.], indomethacin (10 mg/kg, p.o.), L-NAME (10 mg/kg, i.p.), and glibenclamide $(5 \mathrm{mg} / \mathrm{kg}$, p.o.) before the oral administration of $0.2 \mathrm{~mL}$ of ethanol (96\%). The dose selection for these agonists and antagonists were based on our pilot experiments and on literature findings. In each case, animals were pretreated with the specific antagonist 30 min before the use of EOCC.

Statistical analysis

The data are presented as mean \pm SEM of eight animals per group, and the statistical significance between groups was analyzed by one-way analysis of variance followed by Student-Newman-Keul's test. The differences between groups were regarded as significant at $P<0.05$.

\section{RESULTS AND DISCUSSION}

The effects of orally administered EOCC on gastric damage induced by absolute ethanol and aspirin are shown in Table 2 . Orally administered absolute ethanol $(0.2 \mathrm{~mL} /$ animal $)$ and aspirin $(500 \mathrm{mg} / \mathrm{kg}$ ) induced severe gastric mucosal damage. EOCC at the tested doses of 200 and $400 \mathrm{mg} / \mathrm{kg}$ exhibited a dose-unrelated protective effect against ethanol-induced gastric lesions and compared with vehicle group, and the extent of inhibitions for the respective doses used was 88 and $85 \%$. Against aspirin ulceration, the protection was significant at both doses of EOCC, with 76 and 67\% decrease of gastric lesion scores, respectively.

In mice pretreated with $\alpha_{2}$-antagonist yohimbine, the gastroprotective effect of EOCC $(200 \mathrm{mg} / \mathrm{kg})$ on ethanol-induced injury persisted (79.7\%) [Figures 1 and 2]. On the other hand, indomethacin $(10 \mathrm{mg} / \mathrm{kg}$, p.o.) pretreatment almost abolished the protective effect of EOCC (48.5\%). Pretreatment with L-NAME (10 mg/ $\mathrm{kg}$, i.p.) or glibenclamide $(5 \mathrm{mg} / \mathrm{kg}$, i.p.) did not reduce the gastroprotection produced by EOCC ( 85.2 and 100\%, respectively). These data indicate that the gastroprotective effect of EOCC could be mediated by endogenous prostaglandins.

Table 2: Effect of $C$. citratus on gastric damage induced by absolute ethanol and aspirin in mice

Treatment Dose (p.o.) Ethanol lesion area (\%) Aspirin lesion score

\begin{tabular}{llll}
\hline Control & - & $15.99 \pm 2.71$ & $10.63 \pm 1.91$
\end{tabular}

$\begin{array}{llll}\text { EOCC } & 50 & 14.37 \pm 3.45 \quad-\end{array}$

$100 \quad 13.75 \pm 2.24 \quad-$

$200 \quad 1.88 \pm 1.05 * * * \quad 2.50 \pm 0.65 * * *$

$400 \quad 2.25 \pm 1.02 * * * \quad 3.42 \pm 0.97 * *$

Data are presented as mean \pm SEM of eight animals in each group. Gastric damage was induced by oral administration of either absolute ethanol $(96 \%, 0.2 \mathrm{~mL} / \mathrm{animal})$ or aspirin $(500 \mathrm{mg} / \mathrm{kg}), 1 \mathrm{~h}$ after completion of pretreatment with vehicle or EOCC. $* * P<0.01$ and $* * * P<0.001$ vs control (one-way analysis of variance followed by Student-Newman-Keul test) 


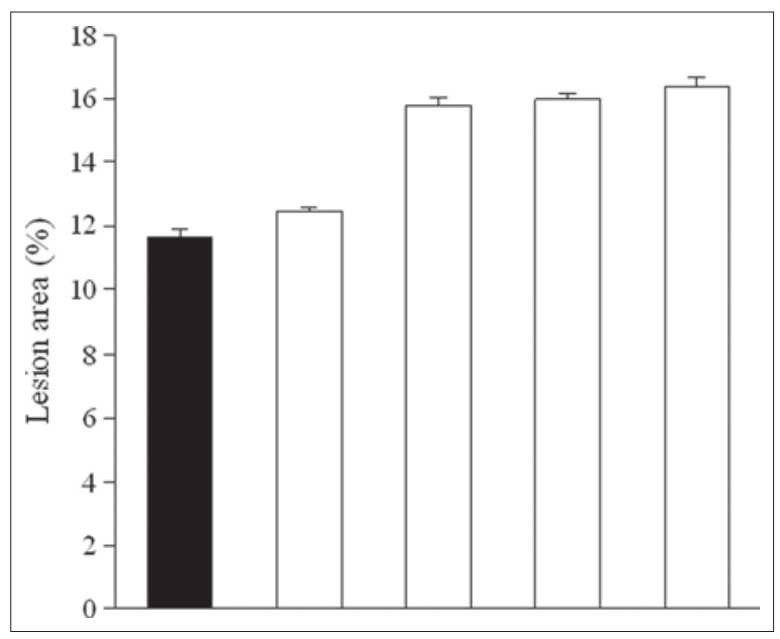

Figure 1: Effect of yohimbine $2 \mathrm{mg} / \mathrm{kg}$ (YO), indomethacin $10 \mathrm{mg} / \mathrm{kg}$ (INDO), L-NAME $10 \mathrm{mg} / \mathrm{kg}$, and glibenclamide $5 \mathrm{mg} / \mathrm{kg}$ (GLIB) in mice on gastric mucosal injury induced by absolute ethanol. The results are shown as mean \pm SEM of eight animals per group (One-way analysis of variance and Student-Newman-Keul's test)

In the recent past, several reports documented the gastroprotective activity of latex, constituents that include flavonoids, oleo-resins, terpenes, xanthones, saponins, alkaloids, and tannins. ${ }^{[10]}$ This study describes for the first time that $C$. citratus has the gastroprotective function. EOCC significantly prevented gastric damage induced by ethanol and aspirin. A lower doses (50 and $100 \mathrm{mg} / \mathrm{kg}$ ) of EOCC did not cause gastroprotection against ethanol injury. It has been firmly established that oxidative stress and impaired prostaglandin synthesis contribute to gastric mucosal damage in experimental models of gastric lesions induced by ethanol. ${ }^{[11]}$

In previous studies, $C$. citratus demonstrated an antioxidant activity in 2,2-Di-Phenyl-1-Picryl-Hydrazyl assay ${ }^{[12]}$ and in the current study; it offered cytoprotection against gastric mucosal damage induced by ethanol and aspirin. By increasing mucosal permeability and release of vasoactive products, ethanol causes vascular damage, and gastric cell necrosis which, in turn, leads to ulcer formation. It has been firmly established that oxidative stress and impaired prostaglandin synthesis contribute to gastric mucosal damage in experimental models of gastric lesions induced by both ethanol and nonsteroidal anti-inflammatory drugs. ${ }^{[10]}$

Some plant-derived substances have been shown to attenuate ethanol- and stress-induced gastric lesions via activation of prostaglandin, nitric oxide, and sensory nerve pathways and thus improving the microcirculation. ${ }^{[13,14]}$ Prostaglandins are of particular importance for the maintenance of gastric mucosal integrity when neuronal defense mechanisms are impaired. ${ }^{[15]}$

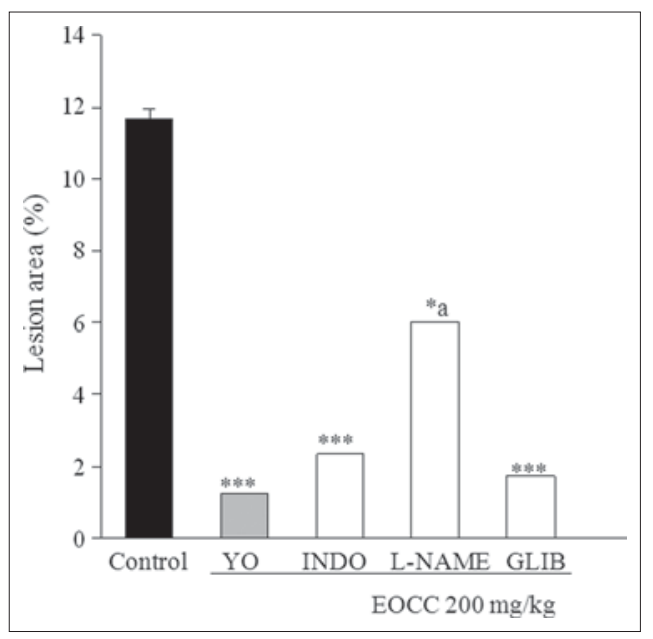

Figure 2: Effect of yohimbine $2 \mathrm{mg} / \mathrm{kg}$ (YO), indomethacin $10 \mathrm{mg} /$ $\mathrm{kg}$ (INDO), L-NAME $10 \mathrm{mg} / \mathrm{kg}$, and glibenclamide $5 \mathrm{mg} / \mathrm{kg}$ (GLIB) on effect of EOCC in mice on gastric mucosal injury induced by absolute ethanol. The results are shown as mean \pm SEM of eight animals per group. ${ }^{*} P<0.05$ and ${ }^{* * *} P<0.01$ vs control; a $P<0.05$ vs EOCC (one-way analysis of variance and Student-Newman-Keul's test)

The ability of EOCC to protect against aspirin-induced gastric ulcers may be due to enhanced synthesis of prostaglandins. On the basis of the results obtained, showing that EOCC exerts a gastroprotective effect against ethanol-induced lesions, we studied the mechanisms involved in such activity. In order to verify the role of prostaglandins in the gastroprotection afforded by EOCC, mice were pretreated with indomethacin, a non-selective cyclooxygenase inhibitor.

Plant extracts are attractive sources of new drugs and have been shown to produce promising results in the treatment of gastric ulcers ${ }^{\left[{ }^{[1]}\right]}$ Natural medicinal products have been used for millennia for the treatment of multiple aliments. Although many have been superseded by conventional pharmaceutical approaches, there is currently a resurgence of interest in the use of natural bioactive products by the general public, with many healthy subjects and patients taking them for the prevention and treatment of multiple conditions, including gastrointestinal disorders and postoperative recovery. ${ }^{[17]}$ Previous reports indicate the gatroprotective effect of Anisomeles indica, ${ }^{[18]}$ Lippia nodiflora, ${ }^{[19]}$ Alpinia calcarata, ${ }^{[20]}$ Camellia sinensis, ${ }^{[21]}$ Achillea wilhelmsii, ${ }^{[22]}$ Neregamia alata, ${ }^{[23]}$ Cissus quadrangularis, ${ }^{[24]}$ and Gymnosporia rotbiana. ${ }^{[25]}$

The results reveal that the gastroprotection by EOCC against ethanol-induced mucosal injury is vulnerable to indomethacin, suggesting a role for endogenous prostaglandins in gastroprotection.

In conclusion, the results of this study indicate a 
cytoprotective role of EOCC affording gastroprotection against gastric damage induced by ethanol and aspirin, which is possibly mediated, in part, by endogenous prostaglandins and suggest that it might serve as a lead compound for future development of novel therapies that combat nonsteroidal anti-inflammatory drug-associated gastropathy.

\section{ACKNOWLEDGEMENTS}

This study was supported by grants from CNPq and FUNCAP. The authors are grateful to Faculty of Juazeiro do Norte for animal supply and CNPq-INCT for excitotoxicity and neuroprotection.

\section{REFERENCES}

1. Sudjarwo SA. Gastroprotective effect of curcumone on ethanol-induced gastric mucosal lesions in rats. Folia Med Indones 2005;41:2.

2. Ko JK, Cho $\mathrm{CH}$, Ogle $\mathrm{CW}$. The vagus nerve and its non-cholinergic mechanism in the modulation of ethanol-induced gastric mucosal damage in rats. J Pharm Pharmacol 1994;46:29-33.

3. Glavin GB, Szabo S. Experimental gastric mucosal injury: Laboratory models reveal mechanisms of pathogenesis and new therapeutic strategies. FASEB J 1992;6:825-31.

4. Suleiman MM, Romanus IO, Sadiq Y. Gastroprotective effect of the crude methanol extract of Terminalia avicennioides in rats. Vet Arhiv 2007;77:345-54.

5. Kvietys PR, Twohig B, Danzell J, Specian RD. Ethanol-induced injury to the rat gastric mucosa. Role of neutrophils and xanthine oxidase-derived radicals. Gastroenterology 1990;98:909-20.

6. Salim AS. Removing oxygen-derived free radicals stimulates healing of ethanol-induced erosive gastritis in the rat. Digestion 1990;47:24-8.

7. Ghosh S, Playford RJ. Bioactive natural compounds for the treatment of gastrointestinal disorders. Clin Sci 2003;104:547-56.

8. Barbosa LC, Pereira UA, Martinazzo AP, Maltha CR, Teixeira RR, Melo EC. Evaluation of the Chemical Composition of Brazilian Commercial Cymbopogon citratus (D.C.) Stapf Samples. Molecules 2008;13:1864-74.

9. Adeneye AA, Agbaje EO. Hypoglycemic and hypolipidemic effects of fresh leaf aqueous extract of Cymbopogon citratus Stapf. in rats. J Ethnopharmacol 2007;12:440-4.

10. de Olinda TM, Lemos TL, Machado LL, Rao VS, Santos FA. Quebrachitolinduced gastroprotection against acute gastric lesions: Role of prostaglandins, nitric oxide and K+ ATP channels. Phytomedicine 2008;15:327-33.

11. Kwiecien S, Brzozwski T, Konturek PC, Konturek SJ. The role of reactive oxygen species in action of nitric oxide-donors on stress-induced gastric mucosal lesions. J Physiol Pharmacol 2020;53:761-73.

12. Cheel J, Theoduloz C, Rodríguez J, Schmeda-Hirschmann G. Free radical scavengers and antioxidants from Lemongrass (Cymbopogon citratus (DC.) Stapf.). J Agric Food Chem 2005;53:2511-7.

13. Zayachviska OS, Konturek SJ, Drozdowicz D, Brzozowski T, Gzhegotsky MR. Influence of plant-originated gastroproteciive and antiulcer substances on gastric mucosal repair. Fiziol Zh 2004;50:118-27.

14. Brzozowiski T, Konturek PC, Drozodowicz D, Konturek SJ, Zayachivska O, Pajdo R, et al. Grapefruit-seed extract attenuates ethanol-and stress-induced gastric lesions via activation of prostaglandin, nitric oxide and sensory nerve pathways. World J Gastroenterol 2004;11:6450-8.

15. Peskar BM, Ehrlich K, Peskar BA. Role of ATP-sensitive potassium channels in prostaglandin-mediated gastroprotection in the rat. J Pharmacol Exp Ther 2002;301:969-74.

16. Akthar MS, Munir M. Evaluation of antiulcerogenic effect of Solanum nigrum, Brassica olerceae and Ocimum basilicum in rats. J Ethnopharmacol 1989;27:163-76.

17. Ghosh S, Playford RJ. Bioactive natural compounds for the treatment of gastrointestinal disorders. Clin Sci (Lond) 2003;104:547-56.

18. Dharmasiri MG, Ratnasooriya WD, Thabrew MI. Gastroprotective effects of Anisomeles indica Kuntze. Pharmacogn Mag 2007;3:245-9.

19. Khalil H, Ismail H, Taye A, Kamel M. Gastroprotective effect of Lippia nodiffora L. extracts in ethanol- induced gastric lesions. Pharmacogn Mag 2007;3:258-61.

20. Arambewela LS, Arawwawala LD, Ratnasooriya WD. Effect of Alpinia calcarata rhizomes on ethanol - induced gastric ulcers in rats. Pharmacogn Mag 2009;5:226-31.

21. Ratnasooriya WD, Fernando TS. Gastric ulcer healing activity of Sri Lankan black tea (Camellia sinensis L.) in rats. Pharmacogn Mag 2009;5:260-5.

22. Niazmand S, Khooshnood E, Derakhshan M. Effects of Acbillea wilhelmsi on rat's gastric acid output at basal, vagotomized, and vagal-stimulated conditions. Pharmacogn Mag 2010;6:282-5.

23. Purushothaman M, Dhanapal R, Balakrishnan M, Srinivasan S, Anbarasu C, Sriram R. Phytochemical and anti-ulcer investigations of the whole plant extract of Neregamia alata wight and Arn. in albino rat model. Pharmacogn Mag 2009;5:19-22.

24. Mallika J, Vijaimohan K, Kannan K. Cissus quadrangularis L. extract attenuates chronic ulcer by possible involvement of polyamines and proliferating cell nuclear antigen. Pharmacogn Mag 2010;6:225-33.

25. Jain AS, Surana SJ. Antiulcerogenic effects of Gymnosporia rothiana (Celastraceae) against different experimental models. Pharmacogn Mag 2009;5:100-4.

How to cite this article: Fernandes CN, De Souza HF, De Oliveria G, Costa J, Kerntopf MR, Campos AR. Investigation of the mechanisms underlying the gastroprotective effect of Cymbopogon citratus essential oil. J Young Pharmacists 2012;4:28-32.

Source of Support: Grants from CNPq and FUNCAP, Conflict of Interest: None declared.

Announcement

\section{“QUICK RESPONSE CODE” LINK FOR FULL TEXT ARTICLES}

The journal issue has a unique new feature for reaching to the journal's website without typing a single letter. Each article on its first page has a "Quick Response Code". Using any mobile or other hand-held device with camera and GPRS/other internet source, one can reach to the full text of that particular article on the journal's website. Start a QR-code reading software (see list of free applications from http://tinyurl.com/yzlh2tc) and point the camera to the QR-code printed in the journal. It will automatically take you to the HTML full text of that article. One can also use a desktop or laptop with web camera for similar functionality. See http://tinyurl.com/2bw7fn3 or http://tinyurl.com/3ysr3me for the free applications. 